\title{
RAGAM SENI DAN BUDAYA MELAYU NUSANTARA PRA ISLAM
}

\author{
Nyayu Soraya \\ Universitas Islam Negeri Raden Fatah Palembang \\ nyayusoraya76@gmail.com
}

\begin{abstract}
Ethnic Malays have abundant historical treasures. Flakes after fragments that are created every time form a mountain of exemplary examples and stories that have not been told. Based on regional, social and cultural aspects, Malay people inhabit a group of islands in Southeast Asia. Passion to build Malay and civilized architecture with the creation of Malay history, Malay has always been welcome with various cultural elements that enter it, but still maintains Malay flavors with their local genius as a filter. The development of Malay culture throughout the archipelago is predominantly influenced by the existence of a common similarity of identity possessed by various interactions and interrelationships.
\end{abstract}

Keywords: arts, culture, Malay Archipelago, pre-Islam

Abstrak: Etnis Melayu memiliki harta sejarah yang amat melimpah. Serpihan demi serpihan yang diciptakan setiap masanya membentuk gunung gemunung keteladanan serta kisah yang tak habis diceritakan. Berdasarkan aspek kewilayahan, sosial, dan budaya, masyarakat Melayu mendiami gugusan kepulauan di Asia Tenggara. Gairah membangun Arsitektur bermasyarakat dan berbudaya melayu mengiringi terciptanya sejarah melayu, sejak dulu melayu sudah welcome dengan berbagai unsur budaya yang masuk di dalamnya, namun tetap mempertahankan citarasa melayu dengan local jenius mereka sebagai penyaringnya. Perkembangan kebudayaan Melayu diseluruh Nusantara dominan dipengaruhi oleh adanya kesamaaan umum identitas yang dimiliki diladasi oleh berbagai interaksi dan interelasi.

Kata kunci: seni, budaya, Melayu Nusantara, pra Islam

\section{A. PENDAHULUAN}

Indonesia merupakan Negara kepulauan di asia tenggara yang banyak di singgahi oleh pedagang-pedagang asing sehingga dari sinilah kebudayaankebudayaan islam mulai memasuki kepulauan Indonesia. Adapun sebelum masuknya islam di Indonesia peradaban yang ada di Indonesia adalah hinduisme dan budhisme yang peninggalanpeninggalannya masih bisa dibuktikan sampai sekarang seperti bangunan candi, relief dan sebagainya.

Etnis Melayu memiliki harta sejarah yang amat melimpah. Serpihan demi serpihan yang diciptakan setiap masanya membentuk gunung gemunung keteladanan serta kisah yang tak habis diceritakan ( M.Dien Madjid, 2013. Hal : 436). Berdasarkan aspek kewilayahan, sosial, dan budaya, masyarakat Melayu mendiami gugusan kepulauan di Asia Tenggara, yang mencakup berbagai negara seperti: Indonesia, Malaysia, Singapura, Thailand, Filipina, bahkan diasporanya sampai ke Madagaskar, Suriname, dan kepulauan Oceania Makronesia, Mikronesia, dan Polinesia ( Muhamad Takari, 2005, hal: 126 ).

Muhammad Zulfahmi (2016, hal: 308) mengatakan bahwa Melayu mampu mewarnai asia tenggara dengan kekentalan identitasnya, sehingga menjadi sangat menonjol perannya. Semua ini didapatkan tidak begitu saja dan sekejap mata namun melalui pergumuan peradan dalam kurun waktu yang lama. Gairah membangun Arsitektur bermasyarakat dan berbudaya melayu mengiringi terciptanya sejarah melayu, sejak dulu melayu sudah welcome dengan berbagai unsur budaya yang masuk di dalamnya, 
namun tetap mempertahankan citarasa melayu dengan local jenius mereka sebagai penyaringnya. Perkembangan kebudayaan Melayu diseluruh Nusantara dominan dipengaruhi oleh adanya kesamaaan umum identitas yang dimiliki diladasi oleh berbagai interaksi dan interelasi. Masyarakat Melayu adalah masyarakat yang dinamis, yang menjunjung tinggi nilai-nilai universal, kebenaran, keadilan, dan menghormati perbedaan. Masyarakat Melayu sejak mula telah menggunakan empat konsep stratifikasi adat: (1) adat yang sebenar adat, (2) adat yang teradat, diadatkan, dan (4) (Muhammad Takari, 2005, hal.126) yang kesemuanya mencirikan melayu sebagai masyarakat humanis yang ramah dalam budayanya.

Menelisik jauh kedalam konteks pemenuhan kebutuhan hidup sehari-hari, manusia akan menciptakan budaya. Cakupan unsur kebudayaan ini meliputi: agama, bahasa, organisasi, ekonomi, teknologi, pendidikan, dan seni. Keseluruhannya dapat berwujud gagasan, kegiatan, maupun artefak. Kesenian atau yang sering juga disebut seni budaya muncul di dalam kebudayaan manusia untuk memenuhi kebutuhan manusia akan aspek keindahan. Dalam ajaran islam, bahwa Allah itu sendiri indah dan Allah menyukai keindahan. Termasuk juga manusia sebagai makhluk ciptaan Allah pastilah membutuhkan keindahan di dalam kehodupannya, demikian pula dalam kebudayaan Melayu.

Dalam makalah ini penulis mencoba menghadirkan gambaran seni dan nudaya melayu pra-islam dimana seni budaya manusia nusantara pada saat itu masih berbau animisme dan dinamisme kemudian berlahan-lahan dimasuki unsur agama Hindu dan Budha.

\section{A. PEMBAHASAN}

\section{Pengertian Seni dan Budaya Melayu Nusantara}

Seni pada mulanya adalah proses dari manusia, dan karena itu merupakan sinonim dari ilmu. Dewasa ini, seni bisa dilihat dalam intisari ekspresi dari kreatifitas manusia, seni juga bisa diartikan dengan sesuatu yang diciptakan manusia yang mengandung unsur keindahan (wikipedia.org) Seni adalah segala sesuatu yang diciptakan manusia yang mengandung unsur keindahan dan mampu membangkitkan perasaan diri sendiri maupun orang lain (http://www. Ilmusahid.com. Berdasarkan definisi ini seni adalah produk keindahan, dimana manusia berusahan menciptakan sesuatu yang indah dan dapat membawa kesenangan.

Ibrahim Khalid (2008,hal: 1) dalam bukunya mengatakaan bahwa Budaya adalah bentuk jamak dari kata budi dan daya yang berarti cinta, karsa, dan rasa. Kata budaya berasal dari bahasa Sansekerta budhayah yaitu bentuk jamak dari kata buddhi yang berarti budi atau akal. Dalam bahasa inggris, kata budaya berasal dari kata culture, dalam bahasa Belanda diistilahkan dengan kata cultur, dalam bahasa Latin, berasal dari kata colera. Menurut Setiadi dalam Ibrahim Chalid mengatakan Colera berarti mengolah, mengerjakan, menyuburkan, mengembangkan tanah (bertani). Menurut Herkovist dalam Soekanto yang dikutip oleh Ibrahim Chalid, untuk memahami esensi hakikat kebudayaan, harus dapat memecahkan paradoksparadoks dalam kebudayaan.

Pada intinya arti seni dan budaya nusantara menurut penulis adalah ekspresi dari kreatifitas manusia nusantara yang keluar dari cipta karsa dan rasa yang mengandung unsur keindahan baik berbentuk bengunan, pahatan, ukiran, suara, ritme bunyi maupun gerakan yang telah melekat padanya.

2. Ragam seni dan budaya melayu nusantara Pra-Islam

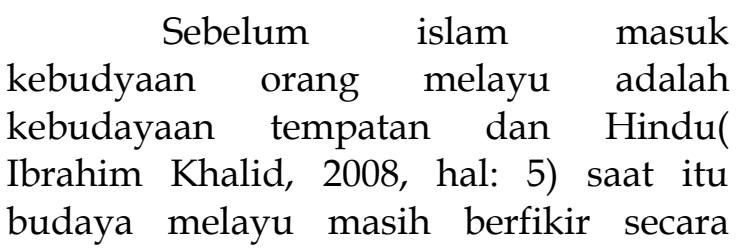


mitos, melayu pra Islam sebenarnya sudah disesaki oleh lantunan syair tradisional yang terendam dalam bentuk mantra-mantra. Ciri yang paling menonjol adalah isinya yang masih animistik, yakni berisi pemujaan atas kayu, laut, sungai, hutan, gunung, hewan dan lain-lain yang dipercaya memberikan kekuatan tertentu bagi perapalnya (M. Dien Madjid, 2013, hal : 446).

\section{Masa Animisme}

Pada era animisme, masyarakat melayu umumnya memusatkan perhatian kepada kebutuhan hidup sehari-hari. Mereka meyakini bahwa di alam ini semua benda dikuasai oleh kekuatankekuatan ghaib. Kemudian mereka melakukan berbagai ritus kepada kekuatan ghaib tersebut. Selanjutnya, mereka melakukan enkulturasi budayanya menggunakan berbagai mitos dan legenda. Melaui ritual ini, mereka juga beraktivitas tari teatrukal. Mereka selalu mengadakan upacara pada siklus musim tertentu. Unsur-unsur religi animisme yang terkandung dalam kebudayaan melayu dapat dipantau dalam penggunaannya dalam masyarkat seperti pada pesta panen padi, sebagai rasa terima kasih kepada yang kuasakuasa ghaib, yang telah mengkaruniai hasil yang melimpah ruah (M. Takari, 2005, hal: 131).

Menurut Nasaruddin dalam Takari (2005, hal. 131) ritual animisme (primitif) terdapat pada masyarakat melayu lama. Salah satu contoh ritual tersebut adalah tari balai raya pada masyarakat Mahameri yang merupakan bagian perayaan dari hari moyang, yaitu hari ulang tahun rohroh. Pada tarian ini,topeng mewakili berbagai moyang atau roh dan sekaligus berfungsi untuk menghormati roh-roh ini.

Di Semenanjung Malaysia dan Pesisir Timur Sumatera Utara, tarian yang mengandung unsur animisme ini, misalnya pada tarian menghadap rebab pada pertunjujam makyong, yang mengidentifikasikan pemujaan terhadap penguasa tanah (jembalang tanah). Begitu juga dengan tari gebuk, yaitu tari pengobatan penyakit yang dianggap sebagai penyakit keturunan di daerah Serdang.

Pada masyarakat melayu pula dijumpai upaca memuja roh, seperti yang dilakukan pada saat awal musim menagkap ikan, para nelayan mengadakan ritual main pantai yang tujuannya untuk mendapat restu para makhluk halus di laut untuk menjaga keselamatan mereka saat menangkap ikan dilaut. Begitu juga dengan para petani, pada saat usai panen mereka mengadakan pertunjukan seperti makyong ${ }^{1}$ dan wayang kulit, yang tujuannya adalah berterima kasih kepada penguasa hutan. Unsurunsur upacara tradisional animisme ini mengalami kontinuitas dalam tari melayu seperti saat membuka dan menutup panggung yang menggunakan berbagai upacara (M. Takari,2005 hal. 131).

\section{Masa Hindu}

India dengan agama Hindu masuk ke dalam kehidupan etnik Melayu pada abad pertama dan kedua Masehi, yang dibawa oleh para penyiar agamanya atau pedagang. Selanjutnya pada abad kedelapan belas. Ketika Penang menjadi basis koloni Inggris di Semenanjung Malaya, daerah ini tunduk ke Madras di India Selatan, sehingga banyak pegawai dan serdadu sepahi orang India yang bekerja pada pemerintah Inggris bertugas di Penang dan Singapura (Sinar).

Menurut Hall dalam Takari, hubungan antara orang-orang India dengan orang-orang Asia Tengggara telah lama terjadi, sejak zaman prasejarah. Daerah Asia Tenggara merupakan bagian yang penting dari rute perdagangan antara India dan Cina. Sumber-sumber kesejarahan dari Cina menyebutkan bahwa masyarakat Melayu juga memainkan peran yang penting dan menjadi pionir dalam hubungan perdagangan ini. Pelabuhan-pelabuhan di Asia Tenggara merupakan pelabuhan yang baik untuk perdagangan antara India dan Cina dan sebagai tempat 
persinggahan. Para pedagang atau pelayar dari Asia Tenggara selalu berkunjung ke India, Srilangka, dan Cina untuk berdagang langsung.

Berbagai unsur budaya India biasanya diasosisikan denganpengaruh India di Asia Tenggara. Ajaran-ajaran Hindu dan Budha, dan konsep-konsep Hindu dikerajaan, dapat dilihat dengan penggunaan teks-teks berbahasa sansekerta, juga penggunaan cerita filosofis seperti Ramayana dan Mahabrata. Arsitektur dan desain agama Hindu, serta dasar bentuk tarian, diserap dan digabungkan dengan unsur-unsur budaya tradisional nusantara, dan terus menerus berinteraksi. Seni arsitektur dengan aroma agama Hindu adalah candi dan juga pahatan di dinding candi (relief), banyak candi yang tersebar di nusantara ini, baik kawasan jawa maupun pulau sumatera namun candi dipulau sumatera tidak sebanyak yang terdapat dipulau Jawa. Kebanyakan candi di Sumatera terletak dilokasi yang cukup jauh dari kota, sehingga tidak banyak wisatawan yang berkunjung kesana. Sebagian besar candi di Kabupaten Mandailing Natal dan Tapanuli Selatan. Sangat sedikit informasi yang telah diketahui tentang keberadaan candi-candi tersebut. Di Samping itu, umumnya lokasi candi cukup jauh dari kota sehingga tidak banyak orang yang mengetahui keberadaannya atau berkunjung kesana. Di Simangambat dekat Siabu, Sumatera Utara, misalnya terdapat reruntuhan candi Syiwa. Diduga candi tersebut dibangun pada abad ke-8 (Raziq hasan, hal: 9).

Kawasan lain di Sumatera Utara yang dikenal mempunyai banyak candi adalah kawasan Padang Lawas, yang mencakup kecamatan Sipirok, Sibuhuan, Sosopan,Sosa, dan Padang Bolak. Di kawasan ini terdapat belaan reruntuhan candi Hindu yang semuanya terletak tidak jauh dari sungai. Sebagian besar terdapat di Kecamatan Padang Bolak. Di Kabupaten Muaro Jambi, Provinsi Jambi, juga terdapat beberapa candi, diantaranya adalah candi Astano, candi Tinggi dan candi Gumpung, candi kembar Baru, candi Gedong, candi Kedaton, dan candi kota Mahligai.

Bentuk bangunan candi dan sisa artikel bersejarah yang dijumpai di Muaro Jambi menunjukkan bahwa bangunan ini berlatar belakang Hinduisme dan diperkirakan dibangun pada abad ke-4 sampai dengan abad ke-5 M. Kemudian untuk seni tari di Sumatera Utara pada dasawarsa 1930-an terdapat tari yang diolah dari unsur-unsur India yang disebut dengan tari chalti, yang iramanya kemudian melahirkan dangdut. Kemudian di Riau terdapat teather Mendu, yakni sebuah teather pengaruh Hindu yang menyebar ke baerbagai tempat-tempat lain seperti Pulau Tujuh yakni: Bunguran Timur (Ranai dan Sepempang), Siantan (Teremapa dan Langi), dan Midai di Pulau Natuna Propinsi kepulauan Riau ( M.Zulfahmi, 2016, hal.314). Dalam bidang musik pula unsur India yang diadun etnik melayu di antaranya adalah penggunaan tabla, gendang Keling (Mardangam), harmonium serta gerenek (improvisasi) lagu dan tangga nada ala raga (namun diolah sesuai dengan estetika mayarakat Melayu ).

\section{Masa Budha}

Unsur yang diadun (diracik) lainnya adalah dari budaya Budha. Kerajaan-kerajaan di Asia Tenggara telah megadakan kontak dengan masyarajat Budha sekitar akhir abad kedua Masehi menurut Hall dan Sheppard dalam Takari (2005: 132). Perdagangan melalui laut terjadi ada abad ketiga Masehi. Kemudian pada abad kelima dan keenam deskripsi tentang keraajaan-kerajaan di Sumatera dan jawa telah dijumpai pada tulisantulisan di Cina. Adanya hubungan antara orang-orang Budha dengan orag-orang melayu dapat diliha dari tulisan dari tulisan penulis Cina yang beragama Budha I-Tsing, yang berkunjung dan menulis tentang Sumatera tahun 671, 685, dan 689 Masehi (Blagden dan Hall). 
Dalam tulisannya I Tsing membicarakan tentang suatu negeri yang disebut dengan Mo-Lo-Yeou dalam tulisan ini dapat diidentifikasi sebagai Melayu yaitu suatu kerajaan yang berada di Jambi, disekitar tepi sungai Batanghari (Hall, 1964) ( M. Takari, 2005, hal.132). Dari segi arsitektur bangunan, unsur agaman Budha juga melekat pada candi seperti halnya di agama Hindu, salah satunya candi yang cukup besar dan terkenal di Sumatera adalah candi Muara Takus yang terletak di Propinsi Riau, tepatnya di Desa Muara Takus, Kecamatam Tigabelas Koto, Kabupaten kampar.

Keberadaan candi diduga mempunyai kaitan erat dengan kerajaan Sriwijaya dan juga dapat dijadikan petunjuk bahwa Muara Takus perna berfungsi sebagai pelabuhan kapal. Hal itu dimungkinkan mengingat orang Sriwijaya adalah pelaut-pelaut yang tangguh yang mampu melayari Sungai Kampar sampai jauh ke arah hulu.

Berbagai unsur Budha, wujud pula dalam seni pertunjukan melayu, misalya teather menhora yang diperkirakan berasal dari Thailand, pada berbagai tarinya mengekspresikan budaya Budha. Di Timur Sumatera ada tari seperti senandung cina atau Inang Cina juga mengadopsi unsur-unsur budaya Budha ini. Dalam musik unnsur Budha (Asia Tenggara)ini dapat dilihat dari penggunaan alat musik ching (simbal kecil dari Thailand). Begitu juga tangga nada anhemitonik pentatonik (lima nada tanpa jarak setengah laras), atau lagu-lagu Melayu yang betangga nada pentatonik kreatif seperti pada lagu senandung Cina, Inang cina, Tudung Periuk, dan lainlainnya.

\section{B. KESIMPULAN}

Nusantara dengan berbagai ragam seni dan budayanya mengajarkan generasi sekarang secara umum untuk mengekspresikan karya seni yang berarti, mengerti sepenuhnya seluk beluk suatu hasil seni serta menjadi sensitif terhadap segi-segi estetika. Apresiasi ini dapat juga diartikan sebagai berbagai pegalaman antara penikmat dan seniman, bahkan ada yang menambahkan, menikmati sama artinya dengan menciptakan kembali Tujuan pokok dari apresiasi ini adalah menjadikan masyarakat " melek seni " sehingga dapat menerima seni sebagai mestnya, menangkap dengan pancaindera, menaggapi, menghayati sampai kepada menilai sesuatu (dalam hal ini karya seni) atau paling tidak kita sebagai pewaris peradaban bisa mempertahankan dan menjaga kelestariannya untuk diberikan kepada generasi selanjutnya.

\section{Referensi}

Ibrahim Chalid, Peradaban Melayu Sebagai Khaazanah Peradaban Nusantara, makalah ini disampaikan pada acara seminar yang bertajuk " Revitalisasi Peradaban Melayu dala Kekinian" (DMDI) di Banda Aceh 20 samapai dengan 25 Agustus.

M. Dien Madjid., Relasi Budaya ArabMelayu dalam sejarah di Indonesia, jurnal al-Turas Vol. XIX No. 2, Juli 2013

Muhammad Takari, Komunikasi dalam seni Pertunjukan Melayu, jurnal Etnomusikologi, Vol.1 No.2, Sepetember 2005

Muhammad Zulfahmi, Interaksi dan Interrelasi Kebudayaan seni Melayu sebagai sebuah proses pembentukan Identitas, jurnal Ekspresi Seni, Vol. 18, No.2, November 2016.

Raziq Hasan, Perkembangan Arsitektur, modul.raziq_hasan.staff.gunadar ma.ac.id 
${ }^{1}$ Makyong adalah seni teather tradisional masyarakat melayu yang sampai sekarang masih digemari dan sering dipertunjukkan sebagai drama tari dalam forum Ibternasional. Dixzaman dulu, pertunjukan makyong diadakan orang desa di Pematang sawah selesai panen padi. Di Kepulauan riau makyong dibawakan penari yang meakai topeng, berbeda dengan Malaysia yang tanpa topeng.

Lihat

https://id.wikipedia.org/wiki/mak_yong 